\title{
ALTERIDADES INDÍGENAS E INTERCULTURALIDADE NO ENSINO SUPERIOR BRASILEIRO: CONTRIBUIÇÕES PARA A ANÁLISE DA IMPLEMENTAÇÃO DA LEI 12.711/2012
}

\author{
Ana Elisa de Castro Freitas ${ }^{1}$ \\ Eduardo Harder $^{2}$
}

\begin{abstract}
Resumo:
No presente artigo busca-se contribuir para as reflexões dedicadas ao processo de exame e debate sobre a primeira década de vigência da Lei Federal n. 12.711/2012, a denominada Lei de Cotas. Focaliza-se a trajetória das políticas afirmativas de ingresso e permanência de jovens indígenas estabelecidas no decurso da democratização do ensino superior brasileiro, seus impasses administrativos e suas potencialidades. Compreende-se que tais políticas inauguram um novo campo de produção de saberes e conhecimentos, cujos contornos epistemológicos se definem e aperfeiçoam na possibilidade efetiva de avanço nos mecanismos políticos e pedagógicos promotores de interculturalidade. Considera-se o desafio de estabelecer um horizonte sistêmico capaz de promover uma articulação entre a educação escolar indígena e a educação superior, expressa em deliberações societárias dos povos indígenas. Por fim, num contexto de crise ambiental, econômica e política, com reflexos na erosão dos direitos sociais, teme-se pelo esvaziamento precoce das ações afirmativas preconizadas na Lei de Cotas, comprometendo não apenas o seguimento da formação da juventude indígena brasileira, mas a agenda democrática do bem comum.
\end{abstract}

Palavras-chave: Lei de Cotas. Educação Superior Indígena. Políticas Afirmativas. Interculturalidade.

\begin{abstract}
:
This article seeks to contribute to the reflections dedicated to the process of examination and debate on the first decade of validity of Federal Law no. 12,711 / 2012, the so-called Quota Law. It focuses on the trajectory of affirmative policies for the entry and permanence of young indigenous people established during the democratization process of Brazilian higher education, their administrative impasses and their potential. It is understood that such policies inaugurate a new field of knowledge production, whose epistemological contours are defined and perfected in the effective possibility of advancing in the political and pedagogical mechanisms that promote interculturality. The challenge of establishing a systemic horizon capable of promoting an articulation between indigenous school education and higher education, expressed in societal deliberations of indigenous peoples, is considered. Finally, in a context of environmental, economic and political crisis, with repercussions on the erosion of social rights, it is feared for the early emptying of the affirmative actions advocated in the Quota Law, compromising not only the follow-up of the formation of Brazilian indigenous youth, but the democratic agenda for the common good.
\end{abstract}

Key Words: Quota Law. Indigenous Higher Education. Affirmative Policies. Interculturality.

\footnotetext{
${ }^{1}$ Docente na Universidade Federal do Paraná, Doutora em Antropologia Social, anaelisa@ufpr.br

${ }^{2}$ Docente na Universidade Federal do Paraná, Doutor em Direito, eduardoharder@ufpr.br
} 


\section{Introdução}

A presença de estudantes indígenas nas universidades brasileiras deflagra um cenário de grande complexidade. Para além dos procedimentos de ingresso e permanência de indígenas no ensino superior, esse cenário inclui um horizonte potencial de aperfeiçoamento acadêmico, administrativo, político e pedagógico das instituições, exigindo ações afirmativas capazes de alargar as esferas deliberativas para acolher a participação igualitária e efetiva dos sujeitos interessados na vida universitária, condição para a interculturalidade.

Sem desconsiderar os ideais do diálogo entre culturas, no presente estudo entende-se a interculturalidade como um chão de práticas que desafia os sujeitos sociais a agirem no cotidiano da universidade pública, repensando e recriando os espaços deliberativos de planejamento, execução, avaliação de programas, normas e projetos institucionais.

Nesse sentido, a interculturalidade é processual e faz parte das metas de democratização das sociedades contemporâneas, reconhecidamente pluriétnicas e multirraciais. Exige dos participantes da vida institucional a superação das desigualdades que se expressam na vida social brasileira, nas quais os povos indígenas são recorrentemente reduzidos e estigmatizados, e que se materializam no cotidiano das instituições em assimetria de poder.

No âmbito pedagógico, entende-se a interculturalidade como construção de pontes que aproximem as sensibilidades envolvidas no projeto educacional, desafiando criticamente as práticas de ensino, pesquisa e extensão arraigadas nas universidades a ampliar seu repertório metodológico, situando em perspectiva crítica os processos de produção nas diversas áreas do conhecimento, revendo temas, fontes, materiais e métodos. Nesse sentido, a interculturalidade é um caminho para a formação da juventude indígena e da juventude brasileira, operando o reposicionamento dos jovens entre si e na esfera pública da sociedade nacional envolvente, bem como junto a suas coletividades de pertencimento.

O desafio do presente artigo reside na proposta de contribuir para as reflexões que se iniciam na extensa rede de intelectuais, estudantes e lideranças indígenas, pesquisadores, defensores e organizações de promoção dos direitos humanos e agentes públicos que se posicionam e intervêm no processo de exame e debate sobre a primeira década de vigência da Lei Federal n. 12.711/2012, a denominada Lei de Cotas. Tais reflexões se fazem necessárias no âmbito do processo de avaliação previsto no artigo $7^{\circ}$ da lei, que trata da revisão do programa especial para o acesso de indígenas junto às instituições de ensino superior.

Para tanto, sob o ponto de vista metodológico, o estudo se orienta pelo exame de alguns marcadores históricos relevantes que ocorreram durante esse período. Os autores consideram 
os avanços decorrentes da implementação do programa de ações afirmativas para a democratização das universidades brasileiras, mas indicam, além de sua necessária manutenção em tempos de políticas de austeridade fiscal, elementos para o seu aperfeiçoamento para a redução das desigualdades e efetiva promoção da justiça e da equidade social. Tal posicionamento está embasado na constatação de que as causas que motivaram o reposicionamento do Estado brasileiro com relação aos procedimentos meritocráticos de ingresso nas instituições de ensino superior no país e suas causas excludentes foram apenas parcialmente mitigadas, permanecendo a estrutura social assimétrica e desigual da sociedade nacional.

Por fim, o artigo destaca que um dos principais riscos às políticas de ação afirmativa reside no esvaziamento de seu legado no cotidiano das universidades, mesmo com sua permanência no plano formal inscrito no ordenamento jurídico nacional, ao restarem cerceadas as condições orçamentárias e de gastos públicos voltadas à promoção de maior igualdade nas condições materiais de existência e na pluralidade e diversidade das posições sociais, tendo por objetivo o aprofundamento da agenda intercultural, a ampliação do cânone democrático e uma vida melhor no futuro.

\section{Problemática}

O cenário das políticas educacionais posterior aos pactos, tratados e convenções ratificados pelo Estado brasileiro, tais como a Convenção 169 da Organização Internacional do Trabalho - OIT (1989), a Declaração Mundial sobre Educação para Todos (1990), a Declaração de Durban (2001) e a Declaração das Nações Unidas sobre os Direitos dos Povos Indígenas (2007) reflete, sob o ponto de vista das normativas do direito internacional, uma série de proposições defendidas pelos povos indígenas em diferentes fóruns de educação.

Boa parcela dessas proposições surgiu no bojo dos processos de territorialização (OLIVEIRA, 1998a; 1998b) e regularização fundiária de terras indígenas instaurado pelo marco jurídico da Constituição Federal brasileira de 1988, bem como em um movimento de retomada de parcelas territoriais ancestrais esbulhadas ao longo do tempo (ROSA, 2015).

No campo do ensino superior, essa conjuntura político-normativa remete a um espaço diferenciado na relação dos povos indígenas com as universidades brasileiras. Se, de um lado, a denominada educação escolar indígena já vinha sendo objeto de uma normatização pelo Estado brasileiro desde 1991 - embora esta normatização muitas vezes entrasse em choque ou não atendesse às pautas que vinham sendo apresentadas pelos intelectuais indígenas -, por outro, havia uma forte omissão deste mesmo Estado no que se refere ao acesso de jovens indígenas ao ensino público superior. 
Até o final da década de 1990, o ingresso de indígenas nas universidades brasileiras estava associado, em regra, a um quadro enxuto de oferta de vagas e bolsas de manutenção em instituições de ensino superior privadas, com fomento advindo, na maior parte das vezes, de fundos internacionais de caráter religioso (FREITAS; ROSA, 2003).

As primeiras iniciativas visando ao acesso específico de estudantes indígenas às instituições públicas de ensino superior ocorreram de forma isolada. As experiências da Universidade de Brasília (2004), da Universidade Federal de Roraima (2002) e da rede de universidades estaduais do Paraná (2001) foram pioneiras e se constituem até hoje referência a outras instituições que gradativamente foram aderindo a essa política.

Esse processo pode ser percebido, no âmbito da administração pública federal, num circuito de eventos sobre educação superior indígena, promovidos inicialmente pelo Ministério da Educação/MEC, entre 2001 e 2004. Neste último ano, houve a criação da Secretaria de Educação Continuada, Alfabetização e Diversidade/SECAD no âmbito do MEC, na qual se instituiu uma Coordenação-Geral de Educação Escolar Indígena/CGEEI (Decreto 2.159/ 2004).

Desde 2003, a Coordenação Geral de Educação/CGE, que então integrava a estrutura administrativa da Fundação Nacional do Índio/FUNAI, vinha mantendo articulação com a CGEEI do MEC, no que se refere à formação de professores, com ação que viria a promover cursos de Magistério Indígena e Licenciaturas nas universidades Federal de Roraima, do Estado do Mato Grosso, do Estado do Amazonas, Federal de Goiás, Federal de Tocantins, Federal da Grande Dourados, Federal de Minas Gerais, entre outras.

Em 2012, a SECAD abarcou explicitamente a finalidade de inclusão e, por meio do Decreto Presidencial n. 7.690/2012, foi reestruturada como Secretaria de Educação Continuada, Alfabetização, Diversidade e Inclusão/SECADI, tendo por objetivo assegurar o direito à educação com qualidade e equidade, por meio de políticas públicas educacionais voltadas para a inclusão social, com amparo no artigo $5^{\circ}$ da Constituição Federal brasileira. Em 2019, ocorreu a extinção da SECADI, por meio do Decreto Presidencial n. 9.465, de 2 de janeiro de 2019.

Durante sua vigência, tal estrutura permitiu, no campo da formação de novos professores indígenas, inserir o debate das licenciaturas indígenas no quadro de cursos ofertados pelas universidades públicas brasileiras. O Programa de Formação Superior e Licenciatura para Indígenas/PROLIND constituiu-se em um elemento aglutinador de iniciativas dessa natureza.

Não obstante, a oferta de vagas não vinculadas exclusivamente à formação de um quadro de professores indígenas e que contemplasse outras áreas de interesse - como saúde, direito e meio ambiente - ingressou, de modo crescente, na agenda política dos movimentos sociais indígenas. Nessa conjuntura, verificou-se uma crescente adesão de universidades 
públicas federais à abertura de vagas específicas, sejam elas suplementares ou por reserva de vagas, para acesso exclusivo de estudantes indígenas, em diversos cursos de graduação (e.g. Universidades Federais do Paraná, do Rio Grande do Sul, do Mato Grosso, de Pernambuco, de Santa Catarina, de São Carlos, do Amazonas, da Grande Dourados, entre outras).

Revisitando essas experiências, constata-se que a oferta de vagas - enquanto política de acesso - não significou, em muitos dos casos, efetiva disposição ao diálogo e recepção das alteridades indígenas no contexto acadêmico. Observa-se um conjunto de relatos de estudantes indígenas que ingressaram nas universidades e, logo a seguir, enfrentaram dificuldades de toda a ordem - administrativas, pedagógicas, políticas, econômicas, interpessoais etc. -, relacionadas à permanência e manutenção nos cursos (FREITAS; HARDER, 2013; HARDER; FREITAS, 2019; LISBOA, 2017).

Tais dificuldades indicam idiossincrasias entre a busca por efetivação dos direitos relacionados ao reconhecimento da diferença e pluralidade étnica e cultural, presentes na sociedade brasileira e, por outro lado, a ausência de estruturas administrativas e práticas pedagógicas nas universidades que possibilitem a permanência e a conclusão dos cursos pelos jovens indígenas. Esse descompasso indica a precariedade dos espaços e mecanismos institucionais de participação e deliberação dos sujeitos interessados, na formulação de critérios, procedimentos e práticas. Resulta, por exemplo, a inadequação de políticas de moradia que reconheçam as especificidades dos estudantes indígenas e sua família, sua mobilidade socioambiental ou calendários letivos que não abarcam critérios capazes de dialogar com os tempos e espaços dos ritos e organizações indígenas, nos quais a presença dos estudantes assume caráter fundamental para a atualização de seu pertencimento originário.

No âmbito da educação escolar indígena, a partir de 2009 ocorreram circuitos regionais e nacionais de fóruns vinculados à implementação dos Territórios Etno-educacionais, instituídos pelo Decreto Federal n. 6.861/2009. Ao incorporar um recorte territorial às políticas públicas de educação escolar indígena, o Estado brasileiro sinalizou a intenção de implementar um novo modelo de gestão que possibilitasse a articulação entre os distintos níveis da educação pública, desde o ensino fundamental ao superior. O reconhecimento das territorialidades indígenas nas políticas educacionais de Estado abriu espaço para a proposição de estratégias político-pedagógicas não uniformizantes, atentas às diversidades socioambientais e às diversas concepções de educação escolar expressas pelos povos indígenas ${ }^{3}$.

\footnotetext{
${ }^{3}$ Esse modelo de gestão centrado na noção de territórios étnicos já havia sido adotado na Política Nacional de Atenção à Saúde Indígena, a partir de 1999, na figura dos Distritos Sanitários Indígenas.
} 
Projetos de ensino, pesquisa e extensão aproximaram os departamentos de Educação e outros, inseridos nas universidades federais, das coletividades indígenas situadas nas zonas urbanas e peri urbanas de abrangência das sedes e campi universitários, iniciando uma reflexão que resultou na configuração de comunidades de práticas compartilhadas entre docentes universitários e educadores dos diversos povos envolvidos nas experiências de educação escolar indígena (e.g. BERGAMASCHI, 2012; PALADINO, 2012). Estas experiências antecederam o ingresso de estudantes indígenas nas universidades públicas e constituíram um lastro importante que merece estudos futuros.

No que diz respeito ao ensino superior, cabe considerar que essa conjuntura nacional da educação escolar indígena ocorreu em sincronia com o movimento de expansão e interiorização das instituições federais de ensino superior, seja por meio de novas unidades - Universidades Federais do Pampa, da Fronteira Sul, do Vale do Jequitinhonha, do Oeste do Pará, do ABC Paulista, do Recôncavo Baiano, entre outras, ou de novos campi, tais como o Setor Litoral da Universidade Federal do Paraná e o Campus Floresta da Universidade Federal do Acre. ${ }^{4}$

As regiões de implantação dessas novas estruturas federais de ensino superior tinham em comum uma defasagem na oferta de políticas públicas de acesso à cidadania bem como especificidades socioambientais singulares. $\mathrm{Na}$ sua maioria superpõem-se total ou parcialmente, a diferentes territórios indígenas, quilombolas, tradicionais. Em diversas dessas experiências observou-se uma tendência à adoção de estratégias político-pedagógicas que articulassem processos educacionais com as dinâmicas socioambientais vivenciadas pelas comunidades regionais, visando à formação de jovens profissionais qualificados para atuar em projetos de "desenvolvimento sustentável” nas suas regiões originárias.

Nesse contexto, a aprovação da Lei Federal n. 12.711/2012, Lei de Cotas, a qual tramitou durante uma década no Congresso Nacional, com base nos princípios de justiça e equidade social, expressos no Acórdão da Arguição de Descumprimento de Preceito Fundamental (ADPF) 186, do Supremo Tribunal Federal, conferiu segurança jurídica às políticas de ações afirmativas no ensino superior que estavam em curso no Brasil. Essa lei universalizou um sistema de cotas para diversos segmentos discentes, inclusive indígenas, em todas as universidades e institutos federais brasileiros (HARDER; FREITAS, 2016).

Foi justamente no encontro desses dois processos educacionais - o da educação escolar indígena e o da redefinição do perfil das instituições de ensino superior públicas federais brasileiras - que se pode estabelecer um campo inovador de relações permeadas pela dimensão

\footnotetext{
${ }^{4} \mathrm{O}$ conjunto dessas novas unidades e sua expansão ocorreram no contexto do Programa EXPANDIR, do MEC e, posteriormente, pelo Programa REUNI.
} 
etnoterritorial. Em tais cenários, os estudantes universitários indígenas figuram como sujeitos paradigmáticos, com um potencial de protagonizar processos sem precedentes na história da educação escolar indígena e da universidade brasileira (SAMPAIO, 2017).

Não é possível deixar de observar que já em 2001 o Estado do Paraná, por meio da Lei Estadual $\mathrm{n}^{\circ} 13.134$, conferiu um caráter sistêmico ao ingresso de estudantes indígenas nas universidades, ao instituir vagas suplementares em todas as instituições públicas estaduais de ensino superior. A Universidade Federal do Paraná (UFPR) aderiu a esse processo com a Resolução 37/2004 de seu Conselho Universitário, ingressando nesse sistema em 2005.

Gradativamente, a meta de efetivação de políticas de educação superior para indígenas passou a exigir atenção, para além da acessibilidade e ingresso, também para a qualificação das estratégias de manutenção e permanência dos estudantes nos cursos. No caso da UFPR, tratase de uma política de alta complexidade, cujo componente discente envolve jovens indígenas pertencentes a diversos povos e regiões do Brasil, o que significa um desafio para as metas da interculturalidade, do bilinguismo, da fusão de horizontes (CARDOSO DE OLIVEIRA, 2002) ou da afirmação das epistemologias do sul e da ecologia de saberes (SANTOS, 2019).

Foram repensadas estratégias que contribuíssem, em curto prazo, para a configuração de um terreno propício à produção de novas sensibilidades, estruturas e práticas acadêmicas que valorizassem ou "levassem a sério" os estudantes indígenas. A esse respeito, Antonio Carlos de Souza Lima (2002, p.27) observa que:

(...) levar a sério a presença de alunos indígenas dentro das universidades implicaria em criar interfaces para o diálogo, por exemplo, incorporando cursos sobre Direito indígena nos curricula das universidades e ter profissionais capazes de ministrá-los. Significaria oferecer cursos de línguas indígenas, mas ministrados por indígenas que não necessariamente precisariam ser portadores de graus universitários, ou contar com xamãs dentro de faculdades da área de saúde, reconhecendo a autoridade intelectual dos portadores de conhecimentos tradicionais. (...)

O que Souza Lima aponta é justamente o nó central que, no transcurso da primeira década de implementação da Lei de Cotas no ensino superior brasileiro, ainda necessita ser desatado: a ruptura com a lógica eurocêntrica nas esferas de ensino, pesquisa e extensão, movimento que deve ocorrer em sincronia com a abertura universitária para que os sujeitos indígenas protagonizem e vivenciem suas lógicas, conhecimentos, técnicas, práticas pedagógicas e políticas em plenitude no contexto da universidade pública (SOUZA LIMA, 2002, 2007).

Consoante a essa perspectiva, Marcos Paulino (2008, p.145) aponta que "os povos indígenas na universidade podem mostrar, com toda a sua pluralidade, que existem outras formas de ser/estar no mundo que vão além da matriz eurocêntrica hegemônica”. Ressalta, 
também, o enorme potencial de sofisticação dos processos de produção de conhecimento relacionado à presença de intelectuais indígenas nas universidades brasileiras, tarefa ainda por realizar. Nos termos do autor:

(...) a universidade enquanto instituição necessita inaugurar uma discussão mais profunda sobre a epistemologia e a episteme. As instituições, com muitos limites, admitem abrir processos seletivos que permitam incorporar representantes dos povos indígenas, e existem lutas para garantir certas condições que assegurem sua presença. Contudo, é forçoso reconhecer que a presença dos indígenas não forçou o debate sobre os próprios saberes universitários, e um suposto diálogo intercultural ainda é assistemático e fragmentado. (PAULINO, 2008, p.150).

A perspectiva aportada por esses autores permanece atual e encontra ressonância nas proposições que vêm sendo sistematizadas pelos próprios intelectuais indígenas no Brasil (CRUZ, 2017; NERES, 2017; ROSA, 2015; FREITAS, 2015). O contexto deliberativo inaugurado pelas contribuições de jovens intelectuais indígenas junto a seus povos de pertencimento fomenta uma série de diretrizes que passam a ser formuladas pelos povos indígenas e que ainda não reverberaram nas universidades e no Estado brasileiro.

Ressalta-se o documento exemplar elaborado pela Comissão Guarani Nhemonguetá, durante a Conferência Local de Educação Escolar Indígena, ocorrida na Terra Indígena M biguaçu, Santa Catarina, a 9 de abril de 2009, no contexto dos eventos preparatórios à I Conferência Nacional de Educação Escolar Indígena. Este documento aporta determinações fundamentais que deveriam ser efetivadas para o aprimoramento das políticas públicas de educação básica e superior indígena no Brasil:

- Demarcação das terras/tekoa Guarani como condição primeira e fundamental para que exista educação Guarani e educação tradicional Guarani. Sem tekoa não há tekó;

- $\quad$ Criação de um Sistema Único de Educação Indígena Guarani ligado ao MEC. Esse sistema deve prever os distritos de educação escolar indígena, como instâncias técnicoadministrativas autônomas, para que nossas comunidades possam exercer controle nas políticas de educação. Entendemos que esses distritos devem ter autonomia financeira e administrativa para que neles seja garantido o respeito à forma de nosso povo pensar, viver e se organizar. Entendemos que essa proposta deve ser levada à debate a todo povo Guarani;

- Que este Sistema respeite as leis nacionais e convenções internacionais de promoção da educação diferenciada indígena, respeitando as necessidades de cada comunidade indígena, sua escola indígena e seus métodos de ensino, desde os níveis iniciais, cursos técnicos, até o Ensino Superior Diferenciado voltado para as necessidades indígenas. Não basta o ensino ser diferenciado no nível fundamental e médio se na universidade os indígenas devem se enquadrar nos sistemas pré-existentes. As universidades públicas devem oferecer cursos 
Cadernos CERU, Série 2, Vol. 31, n. 1, jun. 2020

específicos para indígenas, voltados para atender as diversas demandas das comunidades e executados o mais próximo das aldeias, para evitar deslocamentos. Que este Sistema respeite o interesse de cada povo em ser executado em período integral ou meio período;

- Contratação diferenciada, de professores, anciões e sábios das aldeias, para nossa escola, de acordo com a necessidade e período indicado pelas comunidades;

- Disponibilização de merenda diferenciada que respeite o calendário indígena, elaborado por cada comunidade em seu Projeto Político Pedagógico. Quando há possibilidade seja priorizado o consumo de alimentos produzidos na própria aldeia;

- Contratação diferenciada de merendeiras que respeitem os períodos em que mulheres não poderão cozinhar por estarem na lua (período menstrual), atividade que é proibida na cultura Guarani;

- Não divisão por séries de ensino, mas por níveis de conhecimento, em que serão avaliados os alunos não por notas, mas por avaliação descritiva, e aprovados sem determinação de período de tempo, mas de acordo com o nível de cada aluno avaliado pela escola junto da comunidade;

- Promoção de Ensino Técnico Diferenciado equivalente ao Ensino Médio dentro das Escolas Indígenas e voltado para as necessidades da cultura Indígena;

- Que em todas as instâncias de ensino haja controle social das comunidades e suas organizações;

- Temos que aprofundar discussões em termos de uma educação escolar Guarani pensando em nosso Yvy Rupá/Território Guarani, território este que extrapola as fronteiras nacionais. Iniciar gestões junto aos governos do Cone Sul - Brasil, Argentina, Paraguai, Bolívia e Uruguai, no sentido de pensar políticas para o Guarani enquanto povo. (NHEMONGUETÁ, 2009)

O documento aponta um percurso necessário para a superação de uma perspectiva integracionista subjacente aos processos de escolarização dos povos indígenas bem como para o alargamento do horizonte positivo também inerente a esses processos. O reconhecimento das especificidades socioculturais de cada povo está expresso no documento Guarani, situando os processos de educação formal em diálogo com os processos de educação indígena e um conjunto de aspectos da vida social envolvidos na formação da pessoa indígena.

O reconhecimento do pluralismo étnico e cultural está no centro desse debate, expressando-se em diversas experiências constitucionais latino-americanas (FAJARDO, 2011). Não obstante, muitas rotinas administrativas e processos pedagógicos presentes nas escolas e 
Cadernos CERU, Série 2, Vol. 31, n. 1, jun. 2020

universidades ainda se inscrevem em um quadro vinculado ao paradigma de tutela e integração dos povos indígenas, que, em sua dimensão epistemológica, se traduzem em horizontes eurocêntricos, patriarcais e coloniais.

Nesse sentido, um primeiro problema concernente às estratégias de permanência e manutenção de estudantes indígenas remete à seguinte questão: quem são efetivamente esses estudantes indígenas nas universidades públicas brasileiras, respeitadas suas singularidades étnicas, linguísticas sociopolíticas, epistemológicas?

Trata-se de descolonizar categorias tais como "índio", "silvícola", redutoras e homogeneizantes num contexto de imensa diversidade de povos e sua historicidade, línguas, modelos de organização social, formas produtivas e relação com os ambientes de seus territórios. O próprio termo "estudantes indígenas" oculta um mosaico de especificidades desconhecidas diante da diversidade de pertencimentos, trajetórias, histórias de vida, anseios, expectativas, projetos.

Assim, uma agenda de pesquisas que aponte para o levantamento do perfil dos estudantes universitários e egressos indígenas, suas memórias, narrativas e percursos profissionais coloca-se como prioritária. Essa agenda desdobra-se, no plano prático, na formulação de programas que promovam um efetivo cruzamento das ações de educação escolar e superior indígena com outras políticas públicas nas áreas da saúde, segurança alimentar, meio ambiente, direitos humanos, entre outras, com reflexo nos territórios.

Por exemplo, no processo de planejamento e formulação de ações envolvendo a segurança e soberania alimentares, a proteção de bacias hidrográficas, a atenção à saúde de crianças, mulheres e idosos nas regiões de um determinado território étnico-educacional, acesso à justiça etc. deveria se buscar uma orientação intersetorial que visasse a otimizar e qualificar a descentralização de recursos públicos de modo a contemplar mecanismos de inclusão de profissionais indígenas egressos das universidades públicas em projetos e programas nas mais diversas áreas profissionais em que estes jovens se encontram capacitados, compondo uma inovadora esfera pública deliberativa.

Em outra perspectiva, há também que se considerarem os limites institucionais das universidades brasileiras em suas dimensões sociais, administrativas, políticas, pedagógicas etc., cujas condições não permitem, atualmente, que os estudantes indígenas vivenciem os espaços de vida universitária de forma ampla, satisfatória e prazerosa. Ao contrário, o ambiente universitário brasileiro, em que pesem situações locais diversas, ainda é permeado por preconceitos e estigmas. Não raro esse cotidiano experimentado pelos indígenas é pano de 
fundo central num quadro de evasão por desistência do sistema educacional (HARDER; FREITAS, 2019).

De outro lado, essa tensão permanente constrange de modo direto as possibilidades de realização das subjetividades e intencionalidades indígenas enquanto intelectuais produtores de outras formas de conhecimentos, tecnologias e práticas.

Sob o ponto de vista das instituições de ensino superior brasileiras, o ingresso de estudantes indígenas não ocorreu sem agregar uma conflituosidade intrínseca à democracia substancial, na qual os limites de categorias como "pluralidade", "diversidade" e mesmo o sentido e a natureza da noção de "público" são constantemente questionados e mesmo transpostos.

A par da dimensão institucional, não há como deixar de refletir sobre qual o possível sentido desse ingresso para as comunidades e para os próprios estudantes indígenas. Caberia um olhar sobre as trajetórias de egressos para reconhecer a qualificação das políticas de atenção e promoção da saúde indígena, por exemplo, com o ingresso de médicos, odontólogos, enfermeiras indígenas; ou os avanços nos projetos político-pedagógicos das escolas indígenas quando estas instituições passam a contar com um corpo docente e administrativo composto por profissionais indígenas; ou, ainda, a qualificação de ações de proteção e restauração ambientais orientadas pela ecologia de ambientalistas indígenas formados nas universidades.

O processo de ressignificação de uma instituição social essencial como a universidade corre o risco de ser parcial, caso os estudantes universitários indígenas continuem a ser vistos por muitos com base nos prismas do privilégio, da invisibilidade e do preconceito, desconhecendo a relevância social da formação de sua juventude para o bem comum da sociedade brasileira.

\section{Lei de Cotas: exame e debate sobre a primeira década de vigência}

O posicionamento da Corte Constitucional brasileira na análise das cotas nas universidades, bem como a regulamentação da Lei Federal n. 12.711/2012, por meio do Decreto Federal n. 7.824 e da Portaria Normativa n. 18, ambos de 11 de outubro de 2012, são precários no reconhecimento dos matizes socioambientais representados pelas alteridades indígenas, resultando na assimétrica presença indígena nos textos das normas.

Em estudos anteriores apontamos que a questão indígena aparece de modo residual tanto na Lei de Cotas como na sua regulamentação (HARDER; FREITAS, 2016). Isso revela uma dificuldade nas instituições como o Supremo Tribunal Federal e o Congresso Nacional em lidar com a questão indígena contemporânea. As categorias "pretos, pardos e indígenas" postas na legislação são alvo de críticas por parte dos sujeitos de direito e de pesquisadores, por 
Cadernos CERU, Série 2, Vol. 31, n. 1, jun. 2020

significarem um filtro que reduz e distorce a diversidade étnico-racial a categorias estatísticas do Estado.

Por outro lado, a Lei 12.711/2012 e sua regulamentação por meio do Decreto Federal n. 7.824/2012 e da Portaria Normativa n. 18/2012 referem-se justamente nas estatísticas estatais para estabelecerem as vagas, com recorte regional que não dialoga com os Territórios Etnoeducacionais tampouco com o acúmulo de políticas de educação escolar indígena implementadas nas últimas décadas.

É preciso considerar ainda que, desde a década de 1970, se verifica uma alta complexidade dos processos seletivos de ingresso nas universidades brasileiras com vestibulares que se realizam em fases, cujos critérios de gratuidade nas inscrições estão atrelados às políticas de assistência social de caráter universal e que nem sempre têm capilaridade em terras indígenas, dificultando a utilização desses mecanismos de gratuidade pelos estudantes indígenas.

O mesmo raciocínio poderia ser aplicado ao Exame Nacional do Ensino Médio por meio do qual são ofertadas as vagas do Sistema de Seleção Unificada - SISU, sistema de ingresso em boa parcela das universidades. Ou seja, sem perder de vista a importância da legislação federal instituída em 2012 para a orientação jurídica das universidades, os sistemas locais préexistentes têm se revelado, ao longo desses dez anos, como os mais eficientes.

Tais sistemas preveem a participação e o controle social indígena nos processos de seleção e indicação das vagas, algo que não está previsto no Comitê de Acompanhamento e Avaliação das Reservas de Vagas nas Instituições Federais de Educação Superior e de Ensino Técnico de Nível Médio, instituído pelo artigo $6^{\circ}$ do Decreto Federal n. 7.824/2012, para acompanhar e avaliar a regulamentação da Lei de Cotas.

No âmbito institucional local, o aprimoramento da equação na busca de um equilíbrio que resulte em maior correspondência entre o leque de vagas ofertadas e a real demanda de cursos pretendidos pelos povos indígenas, se revela como ponto importante de análise. $\mathrm{O}$ aproveitamento de vagas suplementares, do SISU, específicas ou de cotas tem impacto direto nas taxas de integralização dos cursos, evasão e retenção.

Tomando em consideração o caso da Universidade Federal do Paraná, atualmente há quatro modalidades de ingresso possíveis de serem acessadas por jovens indígenas no ensino superior. As vagas suplementares instituídas pela Resolução 37/2004 do Conselho Universitário permanecem sendo o principal meio de acesso à universidade, embora sejam ofertadas cinco vezes mais vagas de cotas. 
Cadernos CERU, Série 2, Vol. 31, n. 1, jun. 2020

Tais vagas suplementares são ofertadas anualmente por meio do Vestibular dos Povos Indígenas do Paraná, um concurso específico e já amplamente difundido entre os povos indígenas. Por sua vez, as vagas instituídas pela Lei de Cotas são acessadas por meio dos concursos vestibulares convencionais e pelo SISU, mas necessitam ainda de um aprimoramento dos processos seletivos de modo a contemplar no escore classificatório as capacidades etnolinguísticas de candidatos indígenas, como recomenda o mencionado Acórdão da ADPF 186 do Supremo Tribunal Federal.

Além desses sistemas de ingresso, desde 2014 o Setor Litoral da UFPR estabeleceu um sistema de ingresso específico que possibilita o acesso de indígenas ao curso de Licenciatura em Educação do Campo. O curso, com ênfase em ciências da natureza, é de caráter especial e faz parte do Programa Federal PRONACAMPO, criado em 2012, destinado à formação de docentes de escolas do campo. O público-alvo são educadores do campo não licenciados, atendendo ao Decreto Federal n. 7.352/2010, que também abrange agricultores familiares, assentados, acampados, pescadores, ribeirinhas, ilhéus, quilombolas, indígenas e povos da floresta. A cada ano, são oferecidas quarenta vagas na modalidade presencial em regime de alternância, por meio de vestibular especial, que atende aos critérios estabelecidos pelo PRONACAMPO, em consonância com as Diretrizes Operacionais da Educação do Campo, instituídas em abril de 2002, pelo MEC. Especialmente nos últimos dois anos o curso vem tendo procura de um número expressivo de educadores Guarani, correspondendo a $12 \%$ da turma de ingressados de 2018, cujos territórios se situam na região litoral do Paraná, os quais identificam que esse curso atende a suas demandas sociais.

Com relação às vagas suplementares na UFPR, com o passar do tempo observou-se uma crescente defasagem entre a natureza das vagas ofertadas anualmente e a demanda efetiva da juventude indígena. Observa-se uma elevada demanda por cursos da área da saúde, especialmente medicina, e uma oferta de vagas na razão de uma vaga/curso/processo seletivo, de forma que apenas o primeiro classificado pode efetivamente acessar o curso pretendido medicina.

Nesse sentido, observa-se que ambos os sistemas de ingresso - por vagas suplementares, processo seletivo de curso específico e por cotas em processos seletivos convencionais - são de certa forma complementares e que sistematicamente devem ser avaliados e aperfeiçoados, ajustando-se dinamicamente às demandas dos públicos interessados, tendo em vista a otimizar a relação entre vagas ofertadas e demanda, bem como à adequação nos critérios e procedimentos de seleção. 
Em síntese, o sistema de criação de reserva ou de vagas suplementares, ao limitar muitas vezes a oferta de vagas por curso ou processo seletivo a um quantitativo abaixo das expectativas mínimas dos povos indígenas, mostrou-se ineficiente para abarcar uma demanda crescente em diversas áreas profissionais, em especial no campo da saúde, em cursos como Medicina, Odontologia e Enfermagem. Uma consequência indesejada desse processo resultou em vagas ociosas, não preenchidas devido à desistência para reingresso em novo processo seletivo ou migração entre cursos, fatores de evasão e retenção.

Outra constatação reside no deslocamento do foco da demanda formativa do campo das licenciaturas para as áreas da saúde, revelando o caráter dinâmico da demanda por áreas de conhecimento, que deve orientar um sistema de ingresso igualmente dinâmico e flexível, de acordo com os diversos contextos e realidades sociais indígenas e institucionais.

Analisando o conjunto de sistemas de ingresso, o sistema específico criado para atender ao curso de Licenciatura em Educação do Campo no Setor Litoral do Paraná tem demonstrado maior efetividade, se comparado aos demais, no acesso às vagas pelos estudantes indígenas, sugerindo que, quanto maior o corte da especificidade, maior o êxito da modalidade de ingresso, em termos de aproveitamento candidato/vaga. Isso sugere um necessário aperfeiçoamento dos processos de acesso tanto às vagas de cotas como às vagas suplementares. Essa mesma constatação poderia ser aplicada atualmente a outras universidades brasileiras.

\section{Considerações finais}

Ao nos aproximarmos da primeira década de vigência e implementação da Lei de Cotas e quase duas décadas de um conjunto de ações das universidades visando ao ingresso e permanência de indígenas no ensino superior público brasileiro, a demanda por formação da juventude indígena em diferentes áreas profissionais permanece crescente, justificando a continuidade dessas políticas. A avaliação da experiência transcorrida, entretanto, aponta alguns aspectos que merecem ser levados em consideração para a qualificação das políticas de ingresso e permanência de estudantes indígenas no ensino superior.

$\mathrm{O}$ artigo buscou examinar a primeira década de vigência da Lei n. 12.711/2012, a denominada Lei de Cotas, desde o papel desempenhado pelas instituições de ensino superior do país na criação e implementação das políticas de ação afirmativa no Brasil, antecedendo a formulação de uma legislação de abrangência nacional e o posicionamento da Corte Constitucional.

O debate instaurado sobre o reconhecimento das diferentes alteridades que compõem a vida cotidiana da sociedade brasileira ingressou com relativo atraso em nosso país. E a 
Cadernos CERU, Série 2, Vol. 31, n. 1, jun. 2020

institucionalização das políticas de ação afirmativa voltadas aos povos indígenas, nas diferentes instâncias governamentais, instaurou a centelha de uma transformação paradigmática, seja no campo da construção dos conhecimentos, dos direitos culturais, no reconhecimento do efetivo caráter plurinacional ou nas práticas e rotinas administrativas voltadas à execução das políticas públicas.

Um dos principais riscos às políticas de ação afirmativa reside no esvaziamento de seu legado no cotidiano das universidades, mesmo com sua permanência no plano formal inscrito no ordenamento jurídico nacional, ao restarem cerceadas as condições orçamentárias e de gastos públicos voltadas à promoção de maior igualdade nas condições materiais de existência e na pluralidade e diversidade das posições sociais, tendo por objetivo a ampliação do cânone democrático e uma vida melhor no futuro.

Se a vida democrática e a busca por justiça e equidade social constituem a premissa de criação da Lei de Cotas, a radical política de teto de gastos vigente no Brasil aponta para os riscos de esvaziamento das políticas de educação superior, com impactos, sobretudo, para os segmentos populacionais hipossuficientes, como os povos indígenas. Esse cenário envolve a possibilidade de retrocessos na democratização das universidades, em decorrência de um novo ciclo de aprofundamento das desigualdades no acesso ao ensino superior.

\section{Referências bibliográficas}

BERGAMASCHI, Maria Aparecida. Intelectuais indígenas, interculturalidade e educação. Tellus, ano 14, n. 26, p. 11-29, Campo Grande, MS, jan./jul. 2014.

CRUZ, Felipe Sotto Maior. Indígenas Antropólogos e o Espetáculo da Alteridade. Revista de Estudos e Pesquisas sobre as Américas. V.11, n.2, p. 93-108, 2017.

FAJARDO, Raquel Yrigoyen. El horizonte del constitucionalismo pluralista: del multiculturalismo a la descolonización. In: GARAVITO, César Roberto (Org.). El Derecho en América Latina. Un mapa para el pensamiento jurídico del siglo XXI. $1^{\text {a }}$ ed. Buenos Aires: Siglo Veintiuno, p. 139-184, 2011.

FREITAS, Ana Elisa de Castro (Org). Intelectuais indígenas e a construção da universidade pluriétnica no Brasil. Rio de Janeiro: LACED, E-papers, 2015.

FREITAS, Ana Elisa de Castro; ROSA, Rogério Reus Gonçalves da. Diagnóstico do programa de bolsas de manutenção da Diakonishes Werk para estudantes indígenas da Unijuí. Porto Alegre, PPGAS/UFRGS, 2003.

FREITAS, Ana Elisa de Castro; HARDER, Eduardo. "Sobreviver na diferença": o olhar dos "estudantes indígenas" e suas contribuições ao II Encontro de Educação Superior Indígena no Paraná. In: NOVAK, M.S.J. et alii. Educação Superior Indígena no Paraná. Maringá: EDUEM, 2010.

FREITAS, Ana Elisa de Castro; HARDER, Eduardo. Entre equidade social e assimetria de poder: uma análise da implementação de políticas de ação afirmativa de educação superior para indígenas no Brasil. Século XXI, Revista de Ciências Sociais, v.3, nº 1, p.62-87, jan./jun. 2013. 
Disponível em: https://periodicos.ufsm.br/seculoxxi/article/view/11221/pdf. Acesso em: 20 dez. 2019.

HARDER, Eduardo; FREITAS, Ana Elisa de Castro. Estudantes indígenas no ensino superior e os impasses de uma cidadania afirmativa. ABYA-YALA: revista sobre acesso à justiça e direitos nas Américas, v. 3, p. 207-228, 2019.

HARDER, Eduardo; FREITAS, Ana Elisa de Castro. A educação superior para indígenas no discurso da Corte Constitucional brasileira: uma análise do Acórdão da ADPF n.186 do Supremo Tribunal Federal. Revista del Instituto de Investigaciones en Educación. Año 7. N. 8, p.129-142. Resistencia-Chaco-Argentina: Faculdad de Humanidades/UNNE, 2016.

LIMA, Antônio Carlos de Souza. Educação superior para indígenas no Brasil sobre cotas e algo mais. Seminário Formação Jurídica e Povos Indígenas -Desafios para uma educação superior. Belém: LACED. 21-23 mar. 2002.

LIMA, Antônio Carlos de Souza. "Educación superior para indígenas en el Brasil: más allá del sistema de cupos". In: GARCÍA, S.M.; PALADINO, M. (Orgs.). Educación escolar indígena - Investigaciones antropológicas en Brasil y Argentina. $1^{\mathrm{a}}$ ed. Buenos Aires: Antropofagia, 2007.

LISBOA, João Francisco Kleba. Escolarização e intelectuais indígenas: da formação à emancipação. Revista de Estudos e Pesquisas sobre as Américas, v. 11, p. 20-51, 2017.

NERES, Irosangela Correia. Sentimentos e sentidos das experiências vividas por estudantes indígenas na UFPR. Trabalho de Conclusão de Curso. Pedagogia. Curitiba: Universidade Federal do Paraná, 2017.

OLIVEIRA, João Pacheco de (Org.). Indigenismo e Territorialização - Poderes, rotinas e saberes coloniais no Brasil contemporâneo. Rio de Janeiro: Contra Capa, 1998a.

OLIVEIRA, João Pacheco de. Uma etnologia dos "índios misturados"? Situação colonial, Territorialização e fluxos culturais. Mana. [online], vol. 4, n. 1, p. 47-77, 1998b.

OLIVEIRA, Roberto Cardoso de. O Trabalho do Antropólogo. Brasília/São Paulo: Paralelo Quinze/Editora da Unesp, 2002.

PALADINO, Mariana. Algumas notas para a discussão sobre a situação de acesso e permanência dos povos indígenas na educação superior. Práxis Educativa (UEPG. Online), v. 7, p. 175-195, 2012.

PAULINO, Marcos. Povos Indígenas e Ações Afirmativas: o caso do Paraná. 2008. (Dissertação de Mestrado) - FACED/Universidade Federal do Rio de Janeiro, Rio de Janeiro.

ROSA, Douglas Jacinto da. Gestão socioambiental e territorial de terras indígenas sob uma perspectiva Kaingang: um ensaio (auto) etnográfico em Re Kuju - Campo do Meio, bacia hidrográfica do Alto Uruguai, atual Estado do Rio Grande do Sul. Monografia de Conclusão de Curso. Bacharelado em Gestão Ambiental. Matinhos: Universidade Federal do Paraná, Litoral, 2015.

SAMPAIO, Osias Awá-Mboparadjú Guarani Ramos. A universidade como área de influência, no olhar de um guarani. Iluminuras, Porto Alegre, v. 18, n. 43, p. 134-157, jan./jul., 2017.

SANTOS, Boaventura de Sousa. O fim do império cognitivo: a afirmação das epistemologias do sul. Belo Horizonte: Autêntica, 2019. 